\title{
CROSS CULTURE FERTILIZATION SEBAGAI BASIS PENGEJAWANTAHAN KESENIAN DALAM PENDIDIKAN
}

\author{
Jalaluddin Rumi \\ Laborartorial Space, Institut Studi Seni \\ Jl. Magelang Km. 10 Ngancar, Tridadi, Sleman, Yogyakarta 55511 \\ jarumination@gmail.com
}

\begin{abstract}
Cross Culture Fertilization by emphasising on a multicultural understanding in this article, studies the cultural diversity to foster the nation characters, as a basis to implement arts in education. The cultural approach through traditional arts in the education that has a competence in bringing an imaginative-room is a proposition of its idea. It is based on the implementation of elements of traditional arts to grow a natural awareness and to develop a cultural sensitivity on the basic school curriculum in the developed countries. Thus the development circumstance of Indonesian Arts becomes a start image in order to reformulate the traditional arts in the education. By aesthetic experience and artistic reflection, and also comparing with Ki Hadjar Dewantara's education conception of Perguruan Tamansiswa and Visual Culture Learning Community as a study case, this proposition has to get a further study to embody, creatively and innovatively. Thereby the imagination of Cross Culture Fertilization based on the multicultural understanding in Indonesia, holds a central role in the context of its implementation in the education curriculum, nowadays.
\end{abstract}

Keywords: Cross Culture Fertilization; multicultural; traditional arts; aesthetic experience; artistic reflection

\section{Pendahuluan}

Apa dan bagaimana penerjemahan Arts Education menjadi pendidikan seni sebagai sebuah pendekatan dalam mengoptimalkan potensi dan kemampuan anak-didik merupakan wacana kritis dewasa ini. Dapat dilihat pada pelbagai artikel dan seminar nasional maupun internasional yang mengangkat isu tersebut, begitupun pewacanaan perkembangan karakter anak-didik yang terangkum dalam kurikulum 2013. Pada praksisnya sendiri, pengimplementasian pendidikan seni lebih pada pengajaran materi-materi seni dalam kurikulum pendidikan. Hal tersebut dibandingkan dengan Art in Education (seni dalam pendidikan) Broudy, Art as Education (seni sebagai pendidikan) Eisner, dan Art as Experience (seni sebagai pengalaman) Dewey atau yang lebih kompleks lagi oleh Read selaku Education through Art (pendidikan melalui seni), memiliki perbedaan dengan konsepsi kesenian itu sendiri dalam pendidikan untuk menumbuhkan kesadaran natural dan mengembangkan kepekaan kultural anak-didik dalam proses pembelajaran.

Merujuk pada perjalanan disiplin seni-meletakkan kata 'kesenian' dengan perspektif lebih mampu mengejawantahkan model atau corak seni di Indonesia berdasar 
pada kajian-kajian mengenai perkembangannya-dalam institusi pendidikan telah dimasukkan pada kurikulum pendidikan formal dengan nama Pelajaran Kesenian sejak 1975. Klasifikasi dan kapabilitas tenaga didik seni di satu sisi pada dasarnya masih menjadi problematika profesionalitas antara disiplin kesenian dan pendidikan, demikian pula dengan yang dibutuhkan pada sekolah-sekolah dan universitas-universitas. Persoalan mendasar lainnya yaitu kualifikasi universitas negeri kependidikan sebagai tolok ukur kondisi pendidikan kita, di mana institusi seni pada sisi lain, memiliki kebimbangan antara berkarya dan bekerja yang seakan terpisah satu sama lain dengan perubahan sosial ekonomi di masyarakat (Soedarso, 1992).

Problematika ini terjadi karena pembedaan antara pendidikan kesenian sebagai pendidikan vokasional yang bertujuan menguatkan keterampilan teknis berkarya hampir disamakan dengan pendidikan kesenian sebagai pendidikan estetik yang bertujuan mengembalikan pendidikan rasa keindahan (Pamadhi, 2012). Dengan kata lain memposisikan kesenian dalam pendidikan bertujuan untuk membantu pertumbuhan dan perkembangan imajinasi anak-didik berlandaskan 'pengalaman estetik' dan 'percerminan artistik'. Untuk mempertajam kesadaran tersebut dibutuhkan pengevaluasian formulasi terhadap pengejawantahan pendidikan kesenian yakni seperti apa model materi, medium, dan metodenya. Memposisikan kesenian (rupa-musik-tari) selain sebagai suatu pendekatan dalam pendidikan, juga meletakkannya sebagai pijakan untuk melatih olah-rasa anak-didik akan keindahan melalui olah-raga berlandaskan olah-irama. Perihal inilah yang Read (1961) tekankan dari Education through Art:

\begin{abstract}
It must be understood from the beginning that what I have in mind is not merely 'art education' as such, which should more properly be called visual or plastic education: the theory to be put forward embraces all modes of self-expression, literary and poetic (verbal) no less than musical or aural, and forms an integral approach to reality which should be called aesthetic education-the education of those senses upon which consciousness, and ultimately the intelligence and judgment of the human individual, are based. (p. 7)
\end{abstract}

Terlihat jelas kemudian asas dan dasar Pendidikan Kesenian di mana memposisikan imajinasi keindahan menjadi basis pembelajaran dalam rangka untuk memberikan ruangkreatif bagi anak-didik sehingga mampu mengembangkan potensi-konatif dirinya melalui pengalaman estetik dan pencerminan artistik; sehubungan dengan kapabilitas kondisi lingkungan tersebut akhirnya dapat mempertajam kepekaan empatik dan menyuburkan belarasa (compassion) (Sugiharto, 2015); pula menggambarkan kekhasan dari refleksi artistik atas realitas yang terletak dalam kapasitas untuk membongkar mitos-mitos, 
sehingga mampu mengubah kesadaran bagi mereka yang menikmatinya dengan menampilkan kemampuannya yang memungkinkan hidup sehari-hari dapat dialami lagi (Soetomo, 2003). Oleh karena itu, menempatkan konsep dan model kesenian dalam pendidikan berdasar pada bentuk-bentuk keindahan 'tradisional' kita merupakan sebuah wacana untuk dikaji konteksnya di era global kontemporer kini.

Perihal demikian menjadi penekanan bagaimana Eisner (2002) meruangkan seni sebagai model pendekatan di mana aspirasi dan praktek pendidikan dapat diwujudkan dengan memahami proses pembelajaran seperti halnya karakteristik estetika dan memandang perancangan lingkungan pendidikan sebagai sebuah tugas keartistikan. Begitu pula London (2004) melihat ekspresi artistik yang mampu mewujudkan sebuah ruang untuk mengeskpresikan diri secara total dan luas dengan mana keseluruhan dan terintegrasinya pribadi manusia muncul sebagai perintis yang diperlukan dalam sebuah masyarakat yang menyeluruh dan terintegrasi, tidak kurang dari ekspresi artistik yang lengkap dan jelas, maka integrasi akal, raga dan jiwa, serta sebuah pendekatan holistik terhadap pendidikan mesti kita terapkan. Dengan kata lain, bagaimana multikultural dipahami sebagai kualitas kebangsaan untuk direkonstruksi selaku pengalaman estetik dari pencerminan artistik, sehingga dapat membangun imaginasi kebudayaan melalui pendekatan kesenian dalam pendidikan.

Sesuai apa yang diwacanakan oleh Piliang (2011) bahwa untuk mengembalikan masyarakat kontemporer pada kesadaran kulturalnya di belantara citraan dan kepalsuan masyarakat konsumer, maka sebuah ruang bagi pengasahan refleksi diri atas kondisi sekitarnya harus dibangun kembali. Berdasar pada pandangan demikian, maka konsep 'Penyerbukan Silang Antarbudaya' oleh Eddie Lembong dititikberatkan sebagai analisis wacana. Kendatipun, Cross Culture Fertilization (CCF) di mana konsep ini diistilahkan, akan lebih mengkaji secara konseptual potensi kualitas keanekaragaman budaya Indonesia kaitannya terhadap pendekatan kesenian dalam pendidikan untuk menumbuhkembangkan karakter anak-didik. Dengan demikian, dapat ditelaah bahwa persoalan multikultural di Indonesia merupakan kekhasan dan kekuatan dari potensi dan kapasitas kebudayaan bangsa yang mewujud dalam berbagai model kesenian tradisional selaku basis kajian.

\section{Kondisi Perkembangan Pendidikan Kesenian Kita}

Mengkritisi arah dan perkembangan kesenian seperti apa yang dimaksudkan dari awal penerapannya dalam pendidikan di Indonesia oleh karenanya mesti merunut kembali 
sejarah pendirian dua perguruan tinggi kesenian formal pertama, yakni FSRD ITB yang diresmikan pada 1984 (berdiri sebagai Balai Pendidikan Universiter Guru Gambar di bawah Fakultas Ilmu Pengetahuan Teknik Universitas Indonesia di Bandung pada 1947) dan ISI Jogja diresmikan pada 1984 (gabungan dari berdirinya Akademi Seni Rupa Indonesia pada 1949, Akademi Seni Musik Indonesia pada 1961, dan Akademi Seni Tari Indonesia pada 1963), yang kemudian melahirkan institusi-institusi kembangan lainnya, terutama lembaga kesenian dalam pendidikan.

Mengkaji lebih jauh mengenai perjalanan historis pendidikan kesenian di Indonesia, telah terbentuk di Perguruan Tamansiswa pada 1922 oleh Ki Hadjar Dewantara dengan model 'Tri Pusat Pendidikan', 'Tri Rahayu Pendidikan', dan 'Tri Dharma Pendidikan' sebagai pengintegrasian metode Among. Pendekatan kesenian sebagai medium dalam membantu anak-didik untuk merasakan dan mengolah pengenalan kultural sekitar sehingga mampu memahami alam dan dirinya sendiri. Sebutlah kemudian 'dolanan' [permainan tradisional daerah], 'gending' [tembang pengiring dolanan secara sastrawi yang juga dapat dikembangkan ke dalam kegiatan menggambar dan mendengarkan musik], dan 'lakon' [sandiwara mengenai dongeng, mitos, legenda tradisional daerah yang dapat berupa tarian, tutur cerita] —di samping menggambar, menyanyi, serta menari—menjadi stimulisasi pembelajaran dasar di Perguruan Tamansiswa dalam rangka menghadirkan proses pembelajaran guna memahami kondisi alam dan lingkungan kulturalnya sebagai suatu landasan belajar lebih lanjut.

Di sisi lain dengan keanekaragaman kesenian tradisional yang tersebar di berbagai daerah di Indonesia, menggambarkan potensi local genius masing-masing. Adat dan tradisi yang masih lestari, meski sebagian besar telah mengalami perubahan makna pun pula belum mendapat pengkajian serius melalui riset berkelanjutan, juga merupakan sebuah peluang untuk menciptakan local knowledge tersendiri di era globalisasi kontemporer.

Analisis lebih mendalam untuk perihal tersebut, penerapan kesenian tradisional bahkan telah lama diimplementasikan di Cina, Jepang, Australia, Nigeria, Israel, dan Amerika Serikat, ke dalam kurikulum sekolah dasar dalam rangka memperkenalkan anakdidik akan kondisi sosial-budayanya sehingga mampu saling mempelajari keragaman budaya sendiri pada tingkatan selanjutnya, melalui pengembangan pemahaman dan kepekaan estetik/ kesadaran budaya dan kemampuan penciptaan karya kesenian tradisional (Salam, 2000). Pada titik ini, atas pemahaman keanekaragaman kebudayaan melalui kesenian tradisional di Indonesia merupakan bentuk multikultural yang oleh Asosiasi 
Pendidik Seni Indonesia menjadi kajian utama penggagasan Jurnal Pendidikan Seni Kagunan pada 2006; meski tak terlihat perwujudan wacana selanjutnya.

Memasuki abad ke-21 di mana perkembangan begitu cepat teraplikasikan ke berbagai bentuk kelembagaan, mempengaruhi arah dan cara seseorang untuk merespon perkembangan yang ada. Era globalisasi kontemporer menitikberatkan pada pola komoditi dan kebebasan dalam menentukan sikap yang akhirnya berdampak atas kebijakankebijakan politik dan publik. Pengaruh ini pula terasa di lembaga perguruan tinggi baik negeri maupun swasta atas indeks akreditasi universitas. Oleh karena itu seperti yang dipaparkan oleh Soedarso (1992) dalam Beberapa Catatan tentang Perkembangan Kesenian Kita: sebuah kumpulan tulisan oleh berbagai pihak kesenian pada waktu itu sebagai pembacaan atas kondisi kesenian di Indonesia sebelum memasuki abad ke-21, mewacanakan bagaimana pengkajian dan penelitian kritis terhadap kebudayaan dan kesenian tradisional kita merupakan basis pijakan untuk merespon globalisasi yang tanpa hal tersebut akan memberikan kebingungan dalam menentukan arah perkembangan kesenian kita.

Problematika tersebut menggambarkan bagaimana kondisi kesenian dan pendidikan secara umum, dan memperlihatkan kondisi kesenian dalam pendidikan. Meski dewasa ini, berbagai perguruan tinggi negeri dan swasta dalam disiplin pendidikan seni dan atau seni budaya serta seni (rupa, musik, tari) murni penciptaan atau pengkajian telah dikembangkan sedemikian rupa di seluruh daerah Indonesia untuk memenuhi kuota tenaga-pendidik di masyarakat. Dapat dikatakan secara kuantitas yakni kondisi perkembangan pendidikan seni kita telah berkembang jauh sehingga diperlukan evalusi kritis guna mengembangkan kualitas sumber dayanya.

\section{Imaginasi Cross Culture Fertilization}

Seturut dengan imaginasi-hasil dari cipta-rasa-karsa yang diperoleh melalui pemahaman 'kodrat-alam' (pandangan Dewantara) dan 'kodrat-manusia' (pandangan Driyarkara)-ini, yakni memandang manusia secara holistik dalam perspektif keanekaragaman budaya Indonesia. Secara historis, bentuk sederhana silang-budaya (cross culture) memang pernah terlihat pada masa pra-kemerdekaan Indonesia bergotongroyong-mewujudkan ke-bhinneka-an dalam kehidupan berbangsa dan bernegaraberpadu dengan berbagai bentuk pemberontakan di berbagai daerah, memberikan ruang pertemuan bagi seluruh suku bangsa Indonesia untuk saling merasakan dan berjuang 
merebut kemerdekaan. Tentunya di sisi lain tak dapat dihindari munculnya pengakuan identitas antara budaya satu dengan lainnya, kelebihan dan keutamaan antara budaya yang berada di pusat dan di daerah. Olehnya dibutuhkan sebuah regulasi lokal guna memformulasikan suatu kebijakan nasional.

Dari imaginasi ini pula, bagaimana CCF menawarkan sebuah ruang pertemuan antarbudaya yang saling mendukung satu sama lain sebagai pengalaman historis, strategi kebudayan, titik temu keragaman budaya dan agama, dan kritik budaya, memegang peranan penting dalam memberikan pengalaman artistik kepada generasi-pelajar memahami kodratnya sebagai manusia yang memiliki kapasitas dan kualitas masingmasing sesuai dengan kodrat alamnya. Gambaran imajinasi di atas dalam Visual Culture Learning Community (VCLC) telah terbukti, berdasarkan hasil penelitian, mampu membangun kompetensi generasi-didik melalui sistem kolaborasi sebagai sebuah dasar utama terhadap pembelajaran seni-memposisikan seniman selaku subjek studi untuk mengobservasi dan menganalisis proses berkarya sampai pada tahapan pameran — serta bagaimana penerapan kelompok belajar berbasis budaya visual mendukung kemampuan respon dan integrasi sosial (Karpati, Freedman, Castro, Kallio-Tavin \& Heijnen, 2017).

Kualitas budaya dengan ini dapat mudah diamati dari model kesenian dan bentuk keartistikannya yang dipraktekkan oleh masyarakatnya, yakni menjadi sebuah material dasar dalam menganalisis kemungkinan terjalinnya persentuhan antarbudaya dengan saling terbuka mempelajari satu sama lain. Lebih lanjut terhadap potensi ini di Indonesia melalui kesenian tradisional dalam pendidikan, melanjutkan apa yang telah diwacanakan oleh Salam sebelumnya, menggambarkan peluang besar terciptanya suatu penyerbukan silang antarbudaya. Perihal ini, selain mampu menjadi penelitian dan pendokumentasian bersama atas keberagaman kesenian tradisional juga dapat dengan mudah membentuk kesadaran kultural bagi anak-didik sebagai generasi penerus yang memiliki kepribadian kuat dan kemampuan kreatif dari kekayaan pengalaman estetik dan pencerminan artistik secara silang budaya.

\section{Strategi Multikultural}

Dalam pandangan Tilaar (2012) mengenai sebuah konsep yang relatif paling baru dalam khazanah ilmu pengetahuan, mengidentifikasi peran multikultural pada pendidikan sebagai sebuah sistem berkesinambungan, yaitu 1) Lembaga-lembaga pendidikan sebagai pusat kebudayaan; 2) Pendidikan kewargaan; 3) Kurikulum pendidikan multikultural; 4) 
Kebijakan perbukuan; dan 5) Pendidikan guru. Dapat diamati bahwa multikultural memiliki peran penting di era global kontemporer di mana Parekh (2008) membawa Rethinking Multiculturalism: Keberagaman Budaya dan Teori Politik guna mengkaji secara kritis hubungan antara liberalisme dan multikulturalisme dari berbagai tokoh monisme, pluralisme, dan libelarisme untuk mengantar pada pemahaman tentang multikulturalisme yang mana kebudayaan menjadi pijakan kehidupan manusia sehingga tidak tercebur ke dalam kekeliruan pemahaman atas peran multikultural.

Pertanyaan dari Parekh sendiri adalah jika ingin menilai sebuah bentuk kebudayaan maka yang harus menjadi fokus perhatian semestinya yakni nilai-nilai dalam kebudayan tersebut, bukan hanya pada elemen praksisnya. Sehingga seperti yang ditawarkan Tilaar bahwa memang diperlukan sebuah sistem pendidikan yang mampu mencakup khususnya keanekaragaman kebudayaan Indonesia, kualitas-kualitas kebudayaan pada tiap daerah untuk saling dihubungkan nilai-nilainya dalam sebuah kurikulum multikultural yang dilaksanakan oleh lembaga pendidikan independen, yang berkoordinasi dengan pusat pemerintahan nasional di setiap daerah masing-masing dengan model kekhasan kesenian tersendiri.

Strategi multikultural ini yang oleh Dewantara, telah diformulasikan ke dalam Tamansiswa sebagai bentuk model pendidikan berbasis kebudayaan. Pendidikan yang disebut sebagai 'Budi-Pekerti' tentang bagaimana 'ngerti' [mengindra atau mengerti; proses afeksi], 'ngroso' [memahami; proses persepsi]; dan 'nglakoni' [melakukan; proses intuisi] yang sesuai dengan kodrat alam: alam budaya masing-masing; melalui kesenian tradisional. Sehingga apa yang menjadi nilai pokok pada tiap kekhasan budaya Indonesia dapat terekspresikan dan selanjutnya mampu diapresiasi oleh generasi-didik dengan harapan dapat dikreasikan lagi secara kreatif dan inovatif.

Strategi multikultural tersebut juga dilakukan dengan meletakkan kesenian tradisional, dalam pandangan Driyarkara (2006) bahwa persoalan estetika atau pengalaman dan pencerminan dibutuhkan untuk menangkap momen artistik sedemikian guna menumbuhkan kepekaan generasi-didik dari kesadaran akan kodrat alamnya. Pada akhirnya strategi multikultural demi mengaplikasikan CCF memberikan ruang bagi generasi-didik menuju kodrat manusianya. Berdasar pada kualitas artistik melalui pengalaman estetik tersebut, dapat berkontribusi secara spesifik bagi pembelajaran kesenian tradisional terhadap pembentukan karakter kebangsaaan (Gielen, 2017); yang pada ranah selanjutnya, atas pemahaman mendalam mengenai elemen keartistikan akan 
menumbuhkan sikap saling menghormati (Mills, 2018). Dengan berakar pada wacana kritis demikian, diharapkan mampu menggubah-riset yang bersifat konservatif dan kontemplatif-kebudayaan Indonesia yang multikultural berbentuk kesenian dalam pendidikan.

\section{Menggambarkan Kembali Pendidikan Kesenian Kita}

Setelah menempatkan multikultural mengenai posisi CCF yakni sebuah proposisi seperti apa kondisi atau model tawaran untuk memberikan 'ruang-bebas' bagi anak-didik dalam rangka mempelajari dan mengalami langsung suatu pengetahuan melalui pengalaman estetik dari pencerminan artistik. Ruang-bebas yang dimaksud yakni sebuah 'art room' di mana dapat menawarkan tempat pembelajaran khusus selaku lingkungan belajar yang sebenarnya, sehingga mampu membangkitkan memori kultural serta membangun cara baru dalam memikirkan dan merasakan dunia sekitar secara imajinatif dengan beragam bentuk kesenian yang ada dalam art room tersebut (Penketh, 2017). Landasan mengenai ruang-bebas ini menjadikan pelbagai gambar, teks, dan kerajinan sebagai stimulisasi atas persepsi guna melatih kualitas sensorik dan motorik anak-didik secara aural, visual, dan haptik. Sehingga memperjelas rangkaian konsep olah-rasa, olahraga, dan olah-irama dalam pembelajaran pendidikan kesenian.

Mengenai peran estetika terhadap hal tersebut, Dewantara (2004) memandangnya, meskipun muncul dari gerak perasaan tetapi tidak luput dari pengaruh gerak pikiran yang berakar pada jiwa manusia di mana pada tahapan selanjutnya memperkuat nilai-nilai yang terkait di dalamnya. Dengan ini pula, Driyarkara (2006) meletakkan pendidikan estetika dalam proses mengindra bentuk-bentuk kesenian sehingga masuk ke alam pikir dan memunculkan imaginasi tentang sebuah konsep karsa. Dengan kata lain, menggambarkan kembali pengejawantahan pendidikan kesenian adalah dengan mengembalikannya pada pengolahan imajinasi akan keindahan. Kemudian bahwa menempatkan semua yang ada di alam itu memiliki unsur keindahan merupakan sebuah pertimbangan tesis provokatif yang layak dan pijakan dasar bagi lingkungan pendidikan yang estetik (Hettinger, 2017).

Penelaahan lanjutan yaitu formulasi pembelajaran Perguruan Tamansiswa sejak pertama berdirinya dengan menggunakan kesenian tradisional sebagai stimulus untuk membangun kesadaran dan kepekaan terhadap pemahaman atas perbedaan. Sesuai dengan apa yang dicanangkan Smith (2006) mengenai keurgensian pendidikan kesenian yang estetik terhadap kondisi kemanusian kini; "It not only provides criteria of artistic 
excellence and informs aesthetic vision and critical thinking; it also engenders appreciation of difference and contributes to cultural literacy" (p. 120).

Kesinambungan antara pengalaman estetis yang bersandar pada kesenian dan kebudayaan pada pendidikan dalam hal ini, pada dasarnya pula terang Musyafa (2017), menjadi trilogi pendidikan Dewantara dalam Perguruan Tamansiswa: Tri Rahayu Pendidikan: (1) 'Hamemayu Hayuning Sarira' [proses pendidikan yang bermanfaat bagi anak didik dan keluarganya sehingga memiliki kemandirian]; (2) 'Hamemayu Hayuning Bongso' [proses pendidikan kepada seluruh rakyat sehingga mampu bermanfaat bagi nusa dan bangsa]; (3) 'Hamemayu Hayuning Bawono' [proses pendidikan yang berguna bagi kepentingan dunia]; untuk mewujudkan Tri Dharma Pendidikan: (1) 'Ing Ngarso Sung Tulodho' [pemimpin harus mampu memberikan contoh yang baik pada khalayaknya]; (2) 'Ing Madyo Mangunkarso' [pemimpin mesti dapat bekerjasama dengan khalayaknya]; (3) 'Tut Wuri Handayani' [pemimpin harus mampu memberikan kesempatan pada khalayaknya untuk maju dan berkembang sendiri]; di tiap Tri Pusat Pendidikan yakni lingkungan keluarga, lingkungan perguruan, dan lingkungan masyarakat yang berkesinambungan satu sama lain. Sehingga titik temunya berada pada bagaimana memfasilitasi ekosistem belajar berupa ruang-bebas berkualitas pada generasi-didik dengan pendekatan kesenian dan kebudayaan lokal masing-masing, terintegrasi melalui sebuah sistem pendidikan yang mampu mempertemukan keanekaan dalam sebuah keragaman budaya nasional, seperti pada Perguruan Tamansiswa yang kini harus dianalisis kembali pewacanaan dan pengejawantahannya secara kritis.

Lebih lanjut jika ditarik proposisi manifestasinya, akan membawa pada basis konsepsi pendidikan Dewantara dalam Perguruan Tamansiswa yang bersifat sosio-kultural dan berbentuk 'wiyatagraha' atau 'padepokan' (pondok) dengan metode Among serta independen berbentuk yayasan pendidikan nasional. Meski perihal ini merupakan sebuah pertimbangan kritis, tetapi mesti pula mencermati perubahan sosial budaya di masyarakat. Memang penting untuk membentuk pendidikan kesenian secara holistik dan kontemplatif sesuai dengan basis estetiknya dari kekayaan kesenian tradisional di Indonesia, namun di lain hal perlu ada penyesuaian terhadap kondisi perkembangan teknologi dan informasi serta industri kreatif.

Perihal tersebut dapat teramati dengan jelas di Yogyakarata khususnya, yakni menjadi perangkat positif bagi pencipta karya dan audiens serta warga sekitar sebagai medium ekspresi, mengemukakan pendapat, berinteraksi terhadap sesama, meningkatkan 
selera artistik dan juga memperkuat identitas di mana karya tersebut berada di publiknya (Lufiani, Sabana \& Haldani, 2017). Rancangan demikian pula menjadi gambaran kondisi dalam ruang-bebas sebagai lingkungan belajar yang kreatif. Seperti yang ditekankan Joyce \& Weil (1996) yakni tenaga-didik dalam melakukan sebuah proses pendidikan butuh untuk mendesain suatu lingkungan dan kondisi di mana anak-didik akan menjadi tertarik untuk mengalami proses belajar bahwa sekolah pada dasarnya merupakan sebuah ruang-didik yang mampu membimbing pengalaman dan imajinasi anak-didik dalam memperoleh pengetahuan yang diinginkannya secara mandiri. Mendasarkan pengalaman estetik dan pencerminan artistik secara berkesinambungan sebagai dasar pengejawantahan elemenelemen kesenian dalam pendidikan adalah titik kajiannya.

Proposisi sedemikian akhirnya terletak pada pembentukan sebuah ruang-bebasmencakup lingkungan sekolah yang kondusif atas kondisi kultural daerah sekitar dan imajinasi anak-didik dan berintegrasi terhadap lingkungan keluarga dan masyarakatdalam posisi mengejawantahkan kesenian tradisional secara estetik sebagai basis pendidikan untuk kemudian merespon globalisasi kontemporer.Integrasi antara lingkungan sekolah dengan lingkungan keluarga adalah melalui koordinasi penuh dari orang tua ke tenaga-didik, sedangkan dengan lingkungan masyarakat adalah melalui sistem magang sebagai tugas akhir mata pelajaran.

Kesemuanya itu berlandaskan gagasan CCF: menghubungkan dimensi-dimensi kultural di tiap lingkungan pendidikan secara kreatif. Adapun komparasi visi untuk memperdalam interpretasi atas gambaran proposisi di atas yaitu merangkaikan aspek-aspek kualitas kesenian, memahami bentuk dan pengejawantahan kesenian, menekankan perwujudan dalam meng-ekspresikan keartistikan, mempostulatkan perihal estetika sebagai nilai keindahan alami, lalu merumuskannya ke dalam kebijakan dan kekreatifan dalam merespon kurikulum pendidikan, kemudian mengkomparasikan dan menghubungkan persoalan sosial dan historikal, sehingga mampu menginterpretasikan kompleksitas kontekstual atas pemahaman artistik sebagai perumusan bentuk estetik dari nilai fundamental seni dalam pendidikan (Richmond, 2009).

\section{Kesimpulan}

Sugiharto (2013) dalam bukunya Humanisme dan Humaniora: Relevansinya bagi Pendidikan: merumuskan "Kemampuan menjadikan akar budaya sebagai antenna reseptivitas" (p. 306); untuk mendasari wacana pengembangan karakter bangsa dalam 
merespon globalisasi melalui "Budaya baca-tulis sebagai kunci sikap kritis" (p. 307). Pemahaman atas keanekaragaman budaya menjadi basis strategi pengembangan multikultural dalam kurikulum pendidikan berlandaskan pengejawantahan kesenian tradisional. Dengan kata lain, potensi kebudayaan Indonesia yang multikultural merupakan kualitas kekhasan dengan menggunakan imaginasi CCF sebagai konsep pertemuan antara model kesenian dan kebudayaan satu dengan yang lain ke dalam sebuah ruang-bebas pada lingkungan pendidikan di mana memposisikan konsepsi pendidikan Dewantara pada Perguruan Tamansiswa selaku studi komparatif-kritis.

Di samping itu pula, pemikiran Driyarkara mengenai peran pendidikan estetika dalam membangun kesadaran dan kepekaan generasi-didik dalam proses afeksi dan kognitif di pembelajaran; guna melatih apresiasi, ekspresi, dan kreasi anak-didik melalui pengalaman estetik dan pencerminan artistik. Sehingga ruang-bebas yang tercipta untuk membentuk lingkungan belajar yang kreatif dan inovatif dilakukan dengan memasukkan beragam model dan konsep kesenian (rupa, musik, dan tari) tradisional selaku pijakan respon atas pelbagai pola era global kontemporer. Upaya penginterpretasian kesenian tradisional ke dalam ruang-bebas selain merupakan perangkat stimulisasi secara sensorik (aural, visual, dan haptik) dan motorik (olah-rasa, olah-raga, dan olah-irama) pada proses pembelajaran, juga berperan dalam memperkuat pencerminan artistik dan mengasah pengalaman estetik anak-didik selama proses pembelajaran berlangsung di lingkungan pendidikan. Pada akhirnya atas pandangan demikian, gagasan CCF memiliki peran sentral sebagai basis pengejewantahan kesenian-mencakup kebudayaan Indonesia yang multikultural—ke dalam kurikulum pendidikan yang estetik.

\section{Keterangan}

Cross Culture Fertilization (Penyerbukan Silang Antarbudaya) digagas oleh Eddie Lembong sejak 1999 sehingga terbentuk Nabil Foundation pada 2006 hingga pewacanaan gagasan ini dalam buku Penyerbukan Silang Antarbudaya: Membangun Manusia Indonesia pada 2015, berbentuk bunga rampai tulisan oleh para pemerhati kebudayaan di Indonesia diantaranya yakni J. Oetama \& A. S. Maarif (Kata Pengantar), A. Rukmana, A. Chandra, B. Purwanto, B. Agustono, B. Sudjatmiko, D. Chandraningrum, D. Kwartanada, E. Lembong, N. A. Arsuka, R. Gerung, S. Tan, St. Sularto, S. Somowiyarjo, T. Abdullah, Y. A. Piliang, Y. Latif dan S. Mauludi, serta S. A. Siradj (Renungan Penutup). 
Visual Culture Learning Community adalah sebuah kelompok pemuda yang tergabung dalam bentuk ekspresi dan kreasi di luar dari institusi formal dan tanpa seorang pimpinan. Model kolaborasi ini merupakan proyek penelitian bersama oleh A. Karpati, K. Freedman, J. C. Castro, M. Kallio-Tavin dan E. Heijnen yang dilakukan antara 2010 dan 2014 di lima kota berbeda yakni Amsterdam, Budapest, Chicago, Helsinki dan Hongkong. Melalui wawancara, observasi partisipatif dan analisis pada karya seni, model kerangka kolaborasi kreatif ini mengkaji kelompok-kelompok pelaku seni mencakup grup manga dan cosplay berbentuk seni kontemporer, video fanart, graffiti dan cosplay yang bertujuan untuk mengamati implikasinya terhadap Pendidikan Seni.

\section{Kepustakaan}

Bolo, A. D., Bunyamin, A. S., Sugiharto, B., Samho, B., \& Djunatan, S. (2013). Humanisme dan Humaniora: Relevansinya bagi Pendidikan. Dalam B. Sugiharto (Ed.). Bandung: Pustaka Matahari.

Dewantara, K. H. (2004). Karya Ki Hadjar Dewantara Bagian Pertama: Pendidikan (Cetakan Ketiga). Yogyakarta: Majelis Luhur Persatuan Taman Siswa.

Driyarkara, N. (2006). Karya Lengkap Driyarkara: Esai-esai Filsafat Pemikir yang Terlibat Penuh dalam Perjuangan Bangsanya. Dalam A. Sudiardja, G. B. Subanar, S. Sunardi, \& T. Sarkim (Eds.). Jakarta: Gramedia Pustaka Utama.

Eisner, E. W. (2002). The Arts and the Creation of Mind. New Haven: Yale University Press.

Gielen, P. (2017). Artistic Constitutions of the Civil Domain: On Art, Education and Democracy. International Journal of Art and Design Education, 36(2), 134-140. Diakses dari https://doi.org/10.1111/jade.12146

Hettinger, N. (2017). Evaluating Positive Aesthetics. The Journal of Aesthetic Education, 51(3), 26. Diakses dari https://doi.org/10.5406/jaesteduc.51.3.0026

Joesoef, D. (2018). Bangunlah Jiwanya, Bangunlah Badannya: Buah-buah Refleksi Daoed Joesoef untuk Membumikan Pembangunan Nasional. Dalam R. B. E. A. Nugroho, (Ed.). Jakarta: Penerbit Buku Kompas.

Joyce, B., \& Weil, M. (1996). Models of Teaching. (V. Lanigan, Ed.). Boston: Allyn \& Bacon.

Karpati, A., Freedman, K., Castro, J. C., Kallio-Tavin, M., \& Heijnen, E. (2017). Collaboration in Visual Culture Learning Communities: Towards a Synergy of Individual and Collective Creative Practice. International Journal of Art and Design Education, 36(2), 164-175. Diakses dari https://doi.org/10.1111/jade.12099

Lufiani, A., Sabana, S., \& Haldani, A. (2017). Aesthetic and functions of craft art in public art space. Harmonia: Journal of Arts Research and Education, 17(1), 41-47. Diakses dari https://doi.org/10.15294/harmonia.v17i1.7469

Mills, C. (2018). Artistic Integrity. The Journal of Aesthetics and Art Criticism, 76(1), 920. Diakses dari https://doi.org/10.1111/jaac.12413

Musyafa, H. (2017). Ki Hadjar: Sebuah Memoar. Tangerang Selatan: Penerbit Imania.

Pamadhi, H. (2012). Pendidikan Seni: Hakikat, Kurikulum Pendidikan Seni, Habitus Seni dan Pengajaran Seni untuk Anak. Yogyakarta: UNY Press. 
Parekh, B. (2008). Rethinking Multiculturalism: Keberagaman Budaya dan Teori Politik. Yogyakarta: Kanisius.

Penketh, C. (2017). Inclusion and Art Education: 'Welcome to the Big Room, Everything's Alright.' International Journal of Art and Design Education, 36(2), 153-163. Diakses dari https://doi.org/10.1111/jade.12084

Piliang, Y. A. (2010). Dunia yang Dilipat: Tamasya Melampaui Batas-batas Kebudayaan. Dalam A. Adlin (Ed.). Bandung: Pustaka Matahari.

Read, H. (1961). Education through Art. London: Faber and Faber.

Richmond, S. (2009). Art's Educational Value. The Journal of Aesthetic Education, 43(1), 92-105. Diakses dari https://doi.org/10.1353/jae.0.0031

Rukmana, A., Chandra, A., Purwanto, B., Agustono, B., Sudjatmiko, B., Candraningrum, D.,Latif, Y. (2015). Penyerbukan Silang Antarbudaya: Membangun Manusia Indonesia. Dalam S. Mauludi (Ed.). Jakarta: Elex Media Komputindo.

Salam, S. (2000). Pengajaran Seni Rupa Tradisional: Sebuah Tinjauan Internasional. SENI Jurnal Pengetahuan dan Penciptaan Seni,VIII(1), 1-13.

Smith, R. A. (2006). Culture and the Arts in Education: Critical Essays on Shaping Human Experience. New York: Teachers College Press.

Soedarso, Sp. (1991). Beberapa Catatan tentang Perkembangan Kesenian Kita. Yogyakarta: BP ISI Yogyakarta. (1992). Quo Vadis Calon Guru Seni Rupa Kita. SENI Jurnal Pengetahuan dan Penciptaan Seni, Edisi Khusus, 96-106.

Soetomo, G. (2003). Krisis Seni Krisis Kesadaran. Yogyakarta: Kanisius.

Sularto, S. (2016). Inspirasi Kebangsaan dari Ruang Kelas. Jakarta: Penerbit Buku Kompas.

Sugiharto, B. (2015). Untuk Apa Seni?. Bandung: Pustaka Matahari.

Tilaar, H.A.R. (2012). Kaleidoskop Pendidikan Nasional: Kumpulan Karangan. Jakarta: Penerbit Buku Kompas.

Treurini, F. (2013). Driyarkara: Si Jenthu. Jakarta: Penerbit Buku Kompas.

Wibowo, A. S. (2017). Paideia: Filsafat Pendidikan-Politik Platon. Yogyakarta: Kanisius. 